improvements in outcome over the last decade for women with CHT managed in our unit. Underlying mechanisms for adverse events in women with CHT should be studied and racial differences explored.

\section{PM.45 INCREASED NT - A RETROSPECTIVE AUDIT FROM A UNIVERSITY HOSPITAL}

doi:10.1136/archdischild-2013-303966.127

G Holding, NK Vanes, S Mukherjee. UHCW, Coventry, Coventry, UK

The Aim of this audit was to ensure that our teaching hospital was continuing to provide good quality care for women who were screened and presented with increased nuchal translucency (NT) $>3.5 \mathrm{~mm}$. We had initial difficulty identifying these women.

We identified 54 women with an NT greater than $3.5 \mathrm{~mm}$. The NT mean \pm SD was $5.5 \pm 1.9$. Of these $46 / 54$ (85\%) agreed to an invasive test. Two women were referred to the regional fetal medicine department. Therefore 44 women underwent invasive testing within our department. Mean gestation age was 13 weeks for chorionic villous sampling and 17 weeks for amniocentesis.

All 44 were performed using ultrasound guidance using a 19 or $20 \mathrm{G}$ needle. There was one failed attempt in those undergoing CVS and one with amniocentesis. There were no miscarriages in these women undergoing invasive testing. Five women required anti $\mathrm{D}$ and all received it. None of those undergoing testing had a bloody tap or post procedure infection.

Twelve fetuses had abnormal karotypes with trisomy $13(\mathrm{n}=2)$, trisomy $18(n=4)$, trisomy $21(n=4)$ and Turners $(n=2)$. Of these 8 underwent termination of pregnancy, with 3 women going to term with trisomy 21 and 1 with trisomy 13 .

Despite our unit achieving 100\% compliance with the standards set by the Green-top guideline No8 Amniocentesis and CVS, there was initial difficulty in identifying those with abnormal screening results. As a result of this audit, a computerised logbook of all procedures has been created to help with future auditing.

\section{PM.46 REDUCING THE RISK OF THROMBOSIS AND EMBOLISM DURING THE PUERPERIUM: HOW COMPLIANT ARE PATIENTS WITH THROMBOPROPHYLAXIS TREATMENT?}

doi:10.1136/archdischild-2013-303966.128

CE Hordern, CW Bircher, EC Prosser-Snelling, RP Smith. Norfolk and Norwich University Hospital, Norwich, UK

Introduction Our unit adopted guidelines incorporating the RCOG advice on reducing the risk of thromboembolism in pregnancy and the pureperium ${ }^{1}$ in 2010 . All women with 2 or more risk factors are offered a once daily 7 day course of low molecular weight heparin (LMWH) injections immediately following delivery. A previous study in our unit suggested that $41 \%$ of patients would meet the criteria for postnatal thromboprophylaxis ${ }^{2}$.

Methods Patients were recruited in the antenatal clinic or on the postnatal ward. They were contacted after delivery by telephone and asked a series of questions related to their compliance with thromboprophylaxis.

Results Of 67 patients only 56 (84\%) had completed the full course.

The most common reasons for not completing were: didn't feel it was helping; bruising or wound complications; dislike of needles and forgetting.

Thirteen (19\%) did not feel they received enough information regarding thromboprophylaxis.

Regarding the injections: 40 (61\%) self-injected; 22 (33\%) asked family; 4 (6\%) asked health professionals.
Sixty two (93\%) would take thromboprophylaxis if indicated in a future pregnancy.

Conclusions Reported patient compliance with 7 days of postnatal thromboprophylaxis is high. Most patients are prepared to selfinject although a substantial number required help to administer the injections. The majority would accept the medication if required in a future pregnancy. Some did not feel they had adequate information and this could be addressed in our unit.

\section{REFERENCES}

1. Royal College of Obstetricians and Gynaecologists Green-Top Guideline No. 37a. Reducing the risk of thrombosis and embolism during pregnancy and the puerperium. London: Royal College of Obstetricians and Gynaecologists, 2009.

2. Revell BJ, Smith RP. Thrombosis and embolism in pregnancy and the puerperium, reducing the risk: what proportion of patients reach the threshold for thromboprophylaxis? Obstetric Medicine. 2010; 4: 12-14.

\section{PM.47 LIFESTYLE HABITS IN OBESE PREGNANCY: A CASE-CONTROL STUDY}

doi:10.1136/archdischild-2013-303966.129

KL Lindsay, C Heneghan, CA McGowan, L Brennan, FM McAuliffe. University College Dublin, Dublin, Ireland

Introduction Obesity is rapidly becoming prevalent amongst the obstetric population and has been linked to many complications such as gestational diabetes mellitus, preeclampsia and thromboembolism ${ }^{(1)}$. There is a paucity of literature examining the lifestyle habits of obese pregnant women, which may be contributing to such complications.

Methods Sixty-two obese pregnant women (body mass index (BMI) $30.0-39.9 \mathrm{~kg} / \mathrm{m}^{2}$; mean $=34 \mathrm{~kg} / \mathrm{m}^{2}$ ) were matched by age and ethnicity to 124 non-obese pregnant women (BMI 20.0-29.9 kg/m²; mean $\left.=25 \mathrm{~kg} / \mathrm{m}^{2}\right)$. A structured questionnaire was used to assess self-reported lifestyle habits.

Results Based on self-reported walking and other activities, 39\% of the obese group and $35 \%$ of the control group met current guidelines for exercise in pregnancy ${ }^{(2)}(\mathrm{P}=0.589)$. The obese group were more aware of calories on food labels ( $63 \%$ vs $38 \%$; $\mathrm{P}=0.003$ ) and were more likely to drink low fat milk (53\% vs $28 \% ; \mathrm{P}=0.005)$. Prior to pregnancy, the recommended upper limit for alcohol intake of 11 units or more per week was exceeded by a greater percentage of obese women ( $18 \%$ vs $4 \% ; \mathrm{P}=0.004)$. Smoking during pregnancy was also more prevalent in the obese group $(10 \%$ vs $1 \% ; \mathrm{P}=0.003$ )

Conclusion While obese women appeared to be more aware of certain healthier lifestyle choices, their alcohol intake exceeded that of the control group prior to pregnancy, which may have contributed to a greater calorie intake. Further research is needed into possible causes of maternal obesity, such as actual dietary intakes and food portion sizes. This could aid the development of more effective lifestyle interventions for pregnancy.

\section{REFERENCES}

1. Dennedy, M.C \& Dunne, F. (2010) The maternal and fetal impacts of obesity and gestational diabetes on pregnancy outcomes. Best Practice \& Research Clinical Endocrinology \& Metabolism 24:573-589.

2. ACOG Commitee on Obstetric Practice (2002) Exercise during pregnancy and the post partum period. ACOG Committee Opinion no.267. Obstet Gynecol 99:171-173 (reaffirmed in 2009).

\section{PM.48 A CASE OF HAEMOGLOBIN SUN PRAIRIE IN PREGNANCY}

doi:10.1136/archdischild-2013-303966.130

'JD Unsworth, ${ }^{2} \mathrm{~K}$ Ryan, ${ }^{3} \mathrm{~L}$ Byrd. 'Fairfield General Hospital, Manchester, UK' ${ }^{2}$ Manchester Royal Infirmary, Manchester, UK; ${ }^{3}$ St Mary's Hospital, Manchester, UK 
We describe a case of Haemoglobin Sun Prairie, a rare form of alpha thalassemia, caused by an unstable alpha-2-globin variant created by a point mutation in the gene coding for the globulin structure at codon 130, resulting in an alanine to proline switch. This results in an haemolytic anaemia; characterised by a low mean corpuscular volume, small mean corpuscular haemoglobin but relatively normal mean corpuscular haemoglobin concentration. This 25 year old lady is one of only a small number of people in the world with the condition, and this case report is the first reported case during pregnancy. Fertility is not an issue; her main symptoms being those of anaemia and gross haemaglobinuria, for which she was blood transfusion dependent. Potential pregnancy related complications include premature labour, intrauterine growth restriction and pre-eclampsia. Serial fetal growth scans were undertaken revealing a growth velocity within normal limits and her haemoglobin was maintained at approximately $9 \mathrm{~g} / \mathrm{dl}$, however, at 39 weeks gestation pregnancy induced hypertension developed. This necessitated induction of labour which subsequently resulted in delivery by emergency Caesarean section for presumed fetal distress. The baby had normal cord gases and good APGAR scores. This lady has gone on to have 2 further pregnancies with the delivery of 2 healthy babies. This case report illustrates that when managed appropriately, with close surveillance in a joint obstetric and haematology clinic, with serial fetal growth scans and blood transfusions as and when required, the outcome for both mother and baby are good.

\section{PM.49 REPRODUCTIVE LOSS FROM A MULTIPLE PREGNANCY: HEALTH PROFESSIONALS' PERSPECTIVES}

doi:10.1136/archdischild-2013-303966.131

1J Richards, ${ }^{2} \mathrm{R}$ Graham, ${ }^{3} \mathrm{~N}$ Embleton, ${ }^{4} \mathrm{~S}$ Robson, ${ }^{1} \mathrm{~J}$ Rankin. ${ }^{1}$ Insitute of Health \& Society, Newcastle Upon-Tyne, UK; ${ }^{2}$ School of Geography, Politics and Sociology., Newcastle Upon-Tyne, UK; ${ }^{3}$ Royal Victoria Infirmary, Newcastle Upon-Tyne, UK; ${ }^{4}$ nstitute of Cellular Medicine, Newcastle Upon-Tyne, UK

Objective To provide an in-depth understanding of the experiences of health professionals who care for parents who have had a loss from a multiple pregnancy.

Method A qualitative study involving semi -structured interviews. Participants were recruited from two NHS Tertiary hospital units: a Critical Care Baby Ward and Fetal Medicine department. 26 health professionals from a range of clinical roles were interviewed. Data were analysed using a generative thematic approach.

Results Whilst all health professionals felt confident in administering medical care, they felt less confident when dealing with the bereavement issues of parents who may spend many months in hospital whilst surviving multiples are cared for. Staff often felt that they were 'second guessing' what parents' needs might be and feared 'saying the wrong thing' within daily interactions with parents.

Conclusion Many staff, particularly those in more junior roles, felt that they would benefit from formal bereavement training in order to understand more fully how to react effectively to parents' emotional needs. Staff also felt they lacked information regarding the formal bereavement services available to parents and were unsure as to when it was appropriate to utilise them. The value of experience was also acknowledged however, alongside the need for flexibility of approach in order to react to the specific needs of parents.

\section{PM.50 MATERNITY SERVICES IN THE IRISH MASS MEDIA: AN ANALYSIS OF MEDIA CONTENT FROM 2007-2012}

doi:10.1136/archdischild-2013-303966.132

${ }^{1}$ A Marron, ${ }^{2} \mathrm{G}$ Burke, ${ }^{3} \mathrm{E}$ Devereux, ${ }^{4} \mathrm{M}$ Breen. ${ }^{1}$ University of Limerick, Limerick, Ireland,

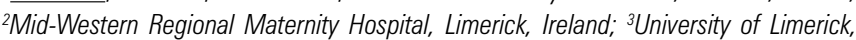
Limerick, Ireland; ${ }^{4}$ Mary Immaculate College, Limerick, Ireland
The mass media play a key role in informing the public about matters of public interest and, critically, in the actual shaping of public opinion about those matters. With this in mind, the purpose of this study was to examine Irish media content and the manner in which it portrays the maternity services in Ireland.

A quantitative content analysis was conducted over the five-year time period from 2007 to 2012. Using the Nexis-Lexis newspaper database, data were sampled from three broadsheet newspapers (the Irish Times, the Irish Independent and the Irish Examiner), one tabloid newspaper (the Irish Daily Mail) and the RTE website. Articles were measured according to a pre-defined coding scheme that included variables such as article placement, storey length, topic, etc. and they were then compared against existing medical statistics.

The results showed that less than $1 \%$ of articles relating to the Irish maternity services received front page treatment over the fiveyear period. Medico-legal processes (18.8\%), budgetary and staffing issues $(15.8 \%)$ and specific high-profile cases of misdiagnosis or inappropriate treatment $(9.7 \%)$ have predominated as the focus of coverage. The more clinical matters, such as breastfeeding $(4.5 \%)$, neonatal care (3.3\%) and post-natal depression (1.2\%), have received relatively little examination.

The need for the public to have access to accurate information about medical matters is clearly of fundamental importance. However, the findings of this research suggest that there is a discrepancy between media representations of these critical issues and the medical realities, which has the potential to undermine public perception.

\section{PM.51 CHALLENGES OF MANAGING PREGNANCY COMPLICATED BY CHRONIC KIDNEY DISEASE STAGES 3-5: A TERTIARY CENTRE'S EXPERIENCE}

doi:10.1136/archdischild-2013-303966.133

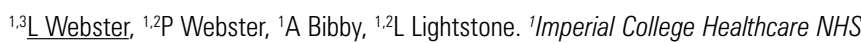
Trust, London, UK; '2Imperial College University, London, UK; ${ }^{3 K i n g}$ 's College Universtiy, London, UK

Objectives Establish the obstetric and neonatal outcomes in women with chronic kidney disease (CKD) stages 3-5 attending renal antenatal clinic from 1999 to present.

Methods All women with excretory renal dysfunction (creatinine $>110 \mu \mathrm{mol} / \mathrm{L}$ or eGFR $<60 \mathrm{ml} / \mathrm{min}$ ) prior to their pregnancy were identified from the Obstetric-Renal database. Outcomes assessed were: small for gestational age (SGA) infants $\left(<10^{\text {th }}\right.$ centile) calculated using the GROW ${ }^{1}$ formula, prematurity (both $<37$ and $<34$ weeks), pre-eclampsia and mode of delivery.

Results 67 pregnancies in 55 women complicated by CKD 3-5 were identified. Three twin pregnancies were excluded from the analysis to prevent confounding of multiple gestation. Sufficient data to calculate birth centile was absent for 21 pregnancies. GROW birth centile was therefore calculated in 43 pregnancies, 14 $(33 \%)$ were below the $10^{\text {th }}$ centile and $25(58 \%)$ were below the $25^{\text {th }}$ centile.

Analysis of all 64 pregnancies revealed 19 babies (30\%) were delivered before 34 weeks and 36 (56\%) were delivered before 37 weeks. All women were delivered before 40 completed weeks. There was one stillbirth at 28 weeks and one neonatal death of a baby born at 31 weeks. 31 (48\%) babies required admission to the neonatal unit. Twelve (19\%) pregnancies were complicated by preeclampsia.

In $8(12 \%)$ pregnancies spontaneous labour occurred and in 24 (38\%) labour was induced. The other $32(50 \%)$ were planned caesarean sections and the total caesarean section rate was $66 \%$.

Conclusions Pregnancies complicated by CKD stages 3-5 are obstetrically high risk and women should enter pregnancy aware of the possible complications. 